\title{
Low dose irradiation profoundly affects transcriptome and microRNAme in rat mammary gland tissues
}

\author{
Lidia Luzhna ${ }^{1}$ and Olga Kovalchuk ${ }^{1}$ \\ ${ }^{1}$ Department of Biological Sciences, University of Lethbridge, Lethbridge, Canada \\ Correspondence to: Olga Kovalchuk, email: olga.kovalchuk@uleth.ca \\ Keywords: mammary gland, low dose radiation, gene expression, microRNAome \\ Received: October 29, $2014 \quad$ Accepted: November 10, $2014 \quad$ Published: November 10, 2014
}

This is an open-access article distributed under the terms of the Creative Commons Attribution License, which permits unrestricted use, distribution, and reproduction in any medium, provided the original author and source are credited.

\section{ABSTRACT}

Ionizing radiation has been successfully used in medical tests and treatment therapies for a variety of medical conditions. However, patients and health-care workers are greatly concerned about overexposure to medical ionizing radiation and possible cancer induction due to frequent mammographies and/or CT scans. Diagnostic imaging involves the use of low doses of ionizing radiation, and its potential carcinogenic role creates a cancer risk concern for exposed individuals. In this study, the effects of $X$-ray exposure of different doses on the gene expression patterns and the micro-RNA expression patterns in normal breast tissue were investigated in rats. Our results revealed the activation of immune response pathways upon low dose of radiation exposure. These included natural killer mediated cytotoxicity pathways, antigen processing and presentation pathways, chemokine signaling pathways, and T- and B-cell receptor signaling pathways. Both high and low doses of radiation led to miRNA expression alterations. Increased expression of miR-34a may be linked to cell cycle arrest and apoptosis. Up-regulation of miR-34a was correlated with down-regulation of its target E2F3 and up-regulation of p53. This data suggests that ionizing radiation at specific high and low doses leads to cell cycle arrest and a possible initiation of apoptosis.

\section{INTRODUCTION}

Ionizing radiation is a powerful tool in medical diagnostics and the most successful cancer treatment after surgery. The major difference in the use of ionizing radiation between diagnostic procedures and radiation therapy is the applied radiation dose. High doses of radiation possess cytotoxic properties required to kill tumor cells [1]. Diagnostic imaging, on the other hand, involves the use of low doses of ionizing radiation to gather the necessary information about a disease without harmful side effects [2]. However, a potential carcinogenic role of ionizing radiation creates a cancer risk concern for exposed individuals. The biological effects of low doses and dose rates of radiation on normal tissues have been the subject of intense research and discussion [3]. According to the Linear-Non-Threshold (LNT) model, low-dose and low-dose-rate exposure results in a similar cancer risk as high-dose exposure [4]. On the other hand, the LNT model is frequently challenged by the hormetic effect theory according to which low doses of radiation may make the exposed cells less susceptible to later high-dose exposure and may have health benefits [5].

Microarray technology for gene expression analysis may provide a better understanding of biological effects of low doses of ionizing radiation. The radiation response at the gene expression level can help reveal the mechanisms of cellular response and identify key genes responsible for specific endpoints [6]. There are only a few published in vivo studies focusing on gene expression analysis in tissues exposed to low doses of ionizing radiation. A clear distinction between high and low doses of gamma radiation has been shown in the liver tissue of mice [7]. Similar effects of low and high doses of radiation have been found in the thymus tissue of mice, with 2421 and 608 genes being affected after high and low doses, respectively [8]. A different response has been shown for internal low-dose radiation from ${ }^{131}$ I. The response of transcripts has been found to be independent of a dose but rather tissue dependent [3]. Overall, there is no clear 
evidence of an exact mechanism of radiation response at the gene expression level, especially in in vivo models. Some reasons might be tedious animal handling, the heterogeneity of the absorbed dose, a mixture of cell types within a tissue, among others.

Gene expression is strongly regulated by epigenetic modifications, including negative regulation of protein synthesis by microRNAs. Ionizing radiation causes alterations in miRNA expression and subsequently, in protein levels of key regulators of the cell cycle. For instance, 2.5 Gy of X-rays caused upregulation of miR-34a and downregulation of miR-7 in hematopoietic tissues [9]. Targets for miR-34a are oncogenes myc, notch1, e2f3, and cyclinD1; miR-7 targets a regulator of DNA methylation, a lymphoid-specific helicase (LSH). The differential expression of miRNAs in response to different doses of gamma radiation was observed previously in human B lymphoblastic (IM9) cells. Low-dose (0.5 Gy) irradiated cells showed a decrease in onco-miRNAs - miR-20 and 21, while high-dose irradiation (10 Gy) caused upregulation of miR-197 that can stimulate carcinogenesis [10]. It was hypothesized that low doses of irradiation suppressed carcinogenesis, while high doses could promote it, and these effects would be miRNA-mediated.

The aim of this study was to investigate the effects
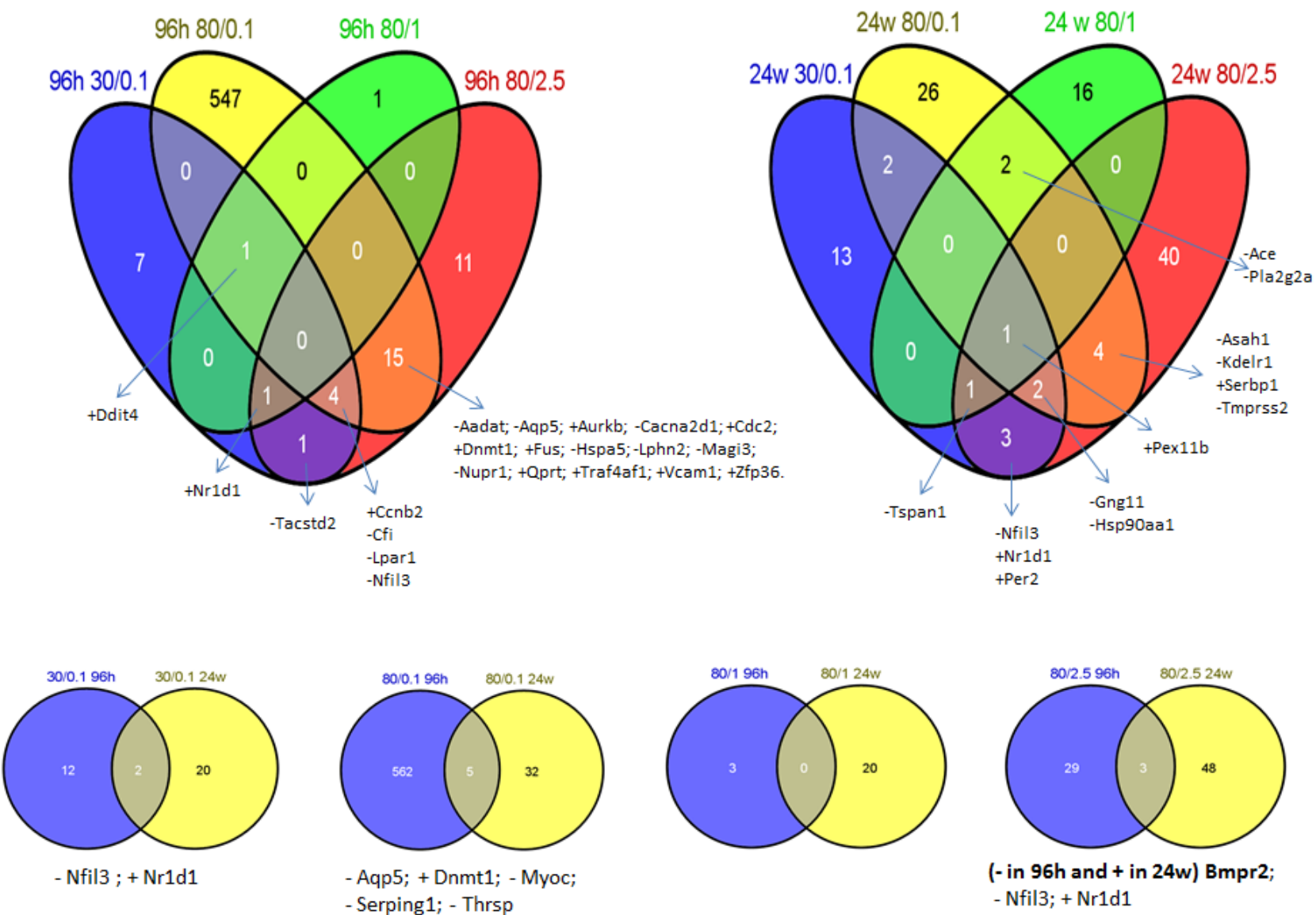

Figure 1: Differentially expressed genes commonly shared between treatment groups. The Venn diagram groups the common altered genes between experimental groups. 
Table 1: Gene expression profiling in mammary gland tissue exposed to low and high doses of ionizing radiation. The number of significantly changed genes in the rat mammary gland upon low energy level/low dose $(30 \mathrm{kVp} / 0.1 \mathrm{~Gy})$, high energy level/low dose $(80 \mathrm{kVp} / 0.1 \mathrm{~Gy})$, high energy level/medium dose $(80 \mathrm{kVp} / 1 \mathrm{~Gy})$ and high energy level/high dose $(80 \mathrm{kVp} / 2.5 \mathrm{~Gy})$ of radiation in comparison to their corresponding un-irradiated controls at 96 hours and 24 weeks time points, as identified by the gene expression profiling analysis.

\begin{tabular}{|c|c|c|c|c|c|c|}
\hline \multirow[b]{2}{*}{$\begin{array}{l}\text { Treatment } \\
\text { Group }\end{array}$} & \multicolumn{3}{|c|}{96 hours } & \multicolumn{3}{|c|}{24 weeks } \\
\hline & $\begin{array}{l}\text { Total } \\
\text { number } \\
\text { of genes } \\
\text { changed }\end{array}$ & $\begin{array}{l}\text { Number } \\
\text { of up- } \\
\text { regulated } \\
\text { genes }\end{array}$ & $\begin{array}{l}\text { Number } \\
\text { of down- } \\
\text { regulated } \\
\text { genes }\end{array}$ & $\begin{array}{l}\text { Total } \\
\text { number } \\
\text { of genes } \\
\text { changed }\end{array}$ & $\begin{array}{l}\text { Number } \\
\text { of up- } \\
\text { regulated } \\
\text { genes }\end{array}$ & $\begin{array}{l}\text { Number } \\
\text { of down- } \\
\text { regulated } \\
\text { genes }\end{array}$ \\
\hline $30 \mathrm{kVp} / 0.1 \mathrm{~Gy}$ & 14 & 8 & 6 & 22 & 8 & 14 \\
\hline $80 \mathrm{kVp} / 0.1 \mathrm{~Gy}$ & 567 & 295 & 272 & 37 & 10 & 27 \\
\hline $80 \mathrm{kVp} / 1 \mathrm{~Gy}$ & 3 & 3 & $\mathbf{0}$ & 20 & 7 & 13 \\
\hline $80 \mathrm{kVp} / 2.5 \mathrm{~Gy}$ & 32 & 13 & 19 & 51 & 28 & 23 \\
\hline
\end{tabular}

Table 2: Significantly altered KEGG pathways in mammary gland upon $96 \mathrm{~h}$ of $80 \mathrm{kVp} / 0.1 \mathrm{~Gy}$ in comparison to the corresponding un-treated controls. In this table, the pathway significance (\%) is defined as the ratio of gene alterations that similarly affect a certain pathway (either up- or down-regulate) to the total number of altered genes in the pathway. "+" - the pathway is up-regulated; "-" - the pathway is down-regulated.

\begin{tabular}{|l|l|}
\hline Pathways & $\begin{array}{l}\text { Pathway Significance, } \\
\% \text { (total number of genes) }\end{array}$ \\
\hline Antigen processing and presentation & $+93.8 \%(16)$ \\
\hline B cell receptor signaling & $+100 \%(13)$ \\
\hline Cell adhesion molecules (CAM) & $+\mathrm{N} / \mathrm{S}(20)$ \\
\hline Chemokine signaling & $+100 \%(14)$ \\
\hline Citrate cycle (TCA) & $-100 \%(8)$ \\
\hline Cytosolic DNA-sensing pathway & $+100 \%(6)$ \\
\hline ECM-receptor interaction & $-88.9 \%(9)$ \\
\hline Fatty acid metabolism & $-100 \%(6)$ \\
\hline Fc epsilon RI signaling & $+100 \%(10)$ \\
\hline Fc gamma R-mediated phagocytosis & $+100 \%(11)$ \\
\hline Glutathione metabolism & $-85.7 \%(7)$ \\
\hline Graft-vs-host disease & $+100 \%(7)$ \\
\hline Hematopoietic cell lineage & $+\mathrm{N} / \mathrm{S}(9)$ \\
\hline Intestinal immune network for IgA production & $+100 \%(6)$ \\
\hline Leukocyte transendothelial migration & $+89.5 \%(19)$ \\
\hline Lysosome & $+\mathrm{N} / \mathrm{S}(13)$ \\
\hline Natural killer cell mediated cytotoxicity & $+100 \%(18)$ \\
\hline PPAR signaling & $-100 \%(10)$ \\
\hline Primary immunodeficiency & $+100 \%(8)$ \\
\hline Pyruvate metabolism & $-100 \%(7)$ \\
\hline T cell receptor signaling & $+100 \%(15)$ \\
\hline Tryptophan metabolism & $-83.3 \%(6)$ \\
\hline & \\
\hline & \\
\hline
\end{tabular}


experimental groups, and there were not many genes common to all the treatment groups (Fig. 1).

Further, we evaluated 567 genes that changed their expression level 96 hours after $80 \mathrm{kVp} / 0.1$ Gy of X-rays: 295 genes were upregulated, and 272 genes were downregulated. With the help of the DAVID functional annotation array analysis tools, we were able to identify and group the evaluated genes according to their function and possible role in certain pathways. Subsequently, genes with a similar or identical function were grouped together; and based on their expression changes, the role of certain pathways in radiation response was evaluated (Table 2). Most of the changed genes contributed to certain immunological pathways (Table 2). Some examples of such elevated pathways are as follows: antigen processing and presentation (16 genes altered), B- and T-cell receptor signaling (13 and 15 genes, respectively), chemokine signaling (14 genes), Fc gamma R-mediated phagocytosis (11 genes), natural killer cell-mediated cytotoxicity (18 genes), etc. Upregulation of immunological pathways reveals the activation of immune defense against possible damages caused by either ionizing radiation or other forms of potential stressors. The visual representation of one of such pathways (natural killer cell-mediated cytotoxicity) is presented in Figure 2. Most downregulated genes contributed to metabolic pathways: citrate cycle (8 genes), fatty acid metabolism (6 genes), glutathione metabolism (7 genes), pyruvate and tryptophan metabolism (7 and 6 genes, respectively) (Table 2). The number of altered genes in the 24 -week $/ 80 \mathrm{kVp} / 2.5$ Gy group was too small to group them in the pathways; therefore, we analyzed singular genes of interest.

The validity of gene expression profiling was confirmed by qRT-PCR for genes with the most change and the greatest radiation response in both the 96 hours $/ 80 \mathrm{kVp} / 0.1$ Gy and 24 weeks $/ 80 \mathrm{kVp} / 2.5$ Gy groups. Therefore, the primary targets for qRT-PCR were cathepsin $\mathrm{K}$ (CTSK), lipocalin 2 (LCN2), phospholipase 2 (Pla2G2), and tetraspanin 1 (TSPAN1) (Fig. 3). CathepsinK, a lysosomal cysteine proteinase that was known to be overexpressed in breast cancers, was significantly elevated at 4 and 24 weeks after high-dose radiation $(80 \mathrm{kVp} / 2.5$ Gy). Lipocalin 2, an oncogene that may function as a growth factor, was also upregulated at 24 weeks after the highest dose of X-rays. Both phospholipase 2 and tetraspanin 1 play a role in cell growth, signaling and

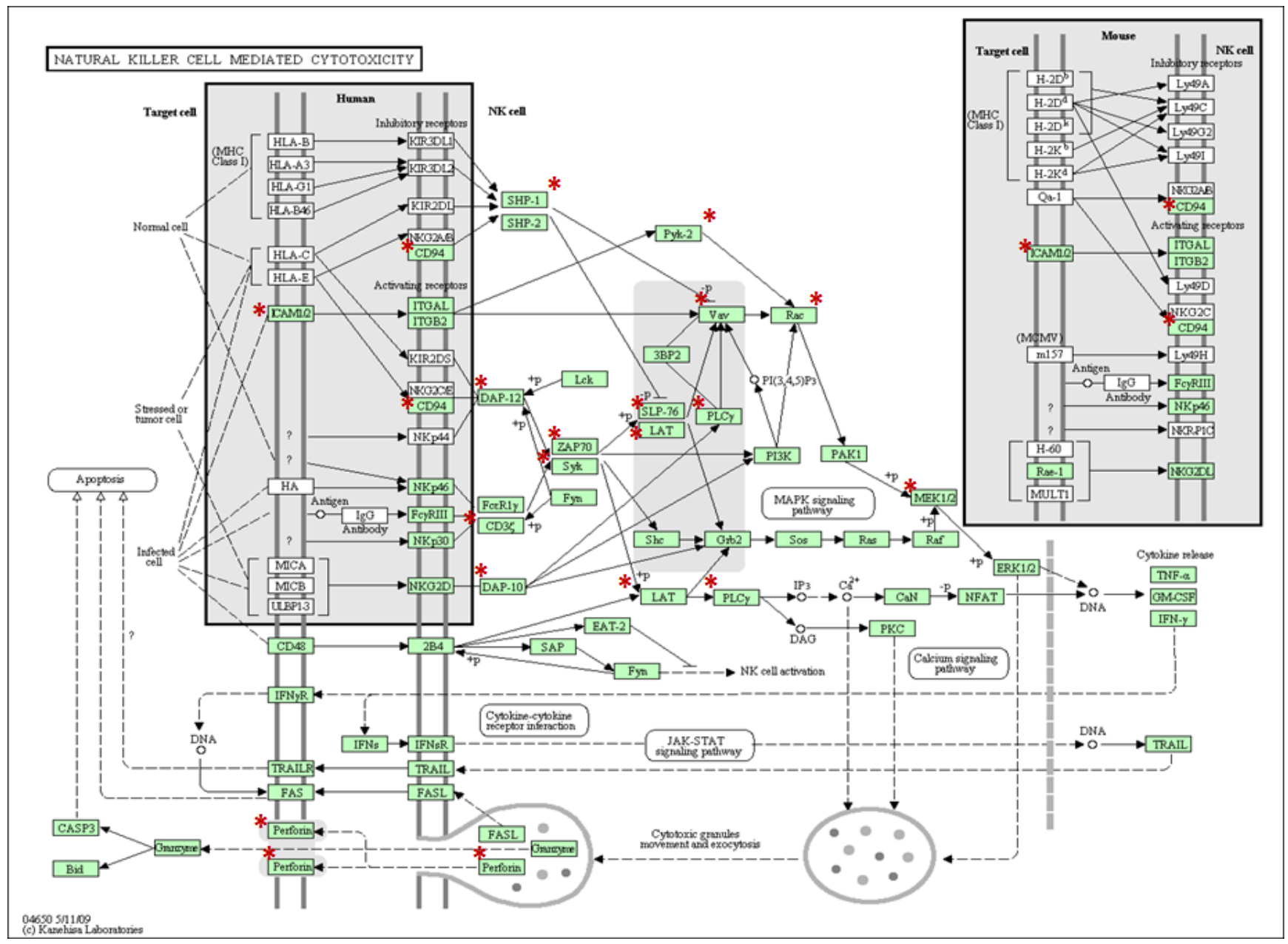

Figure 2: The KEGG Natural Killer Cell Mediated Cytotoxicity Pathway. The red stars represent genes that were upregulated. 
motility. Similarly to the gene expression analysis, qRTPCR showed that these genes were downregulated in most experimental groups at 24 weeks after radiation exposure (Fig. 3).

\section{miRNA expression in the irradiated mammary gland}

miRNAs regulate gene expression epigenetically; therefore, we proceeded to analyze the role of miRNAs in response to low, intermediate, and high doses of radiation in mammary gland tissue at 96 hours after treatment. miRNAs involve the epigenetic control of gene expression regulation through the RNA interference pathway. miRNAs negatively affect the levels of their target transcripts and proteins encoded by these transcripts. In this way, miRNAs contribute to gene silencing, and changes in miRNA expression are common in cancers and in response to radiation.

Interestingly, we identified the alterations in miRNA
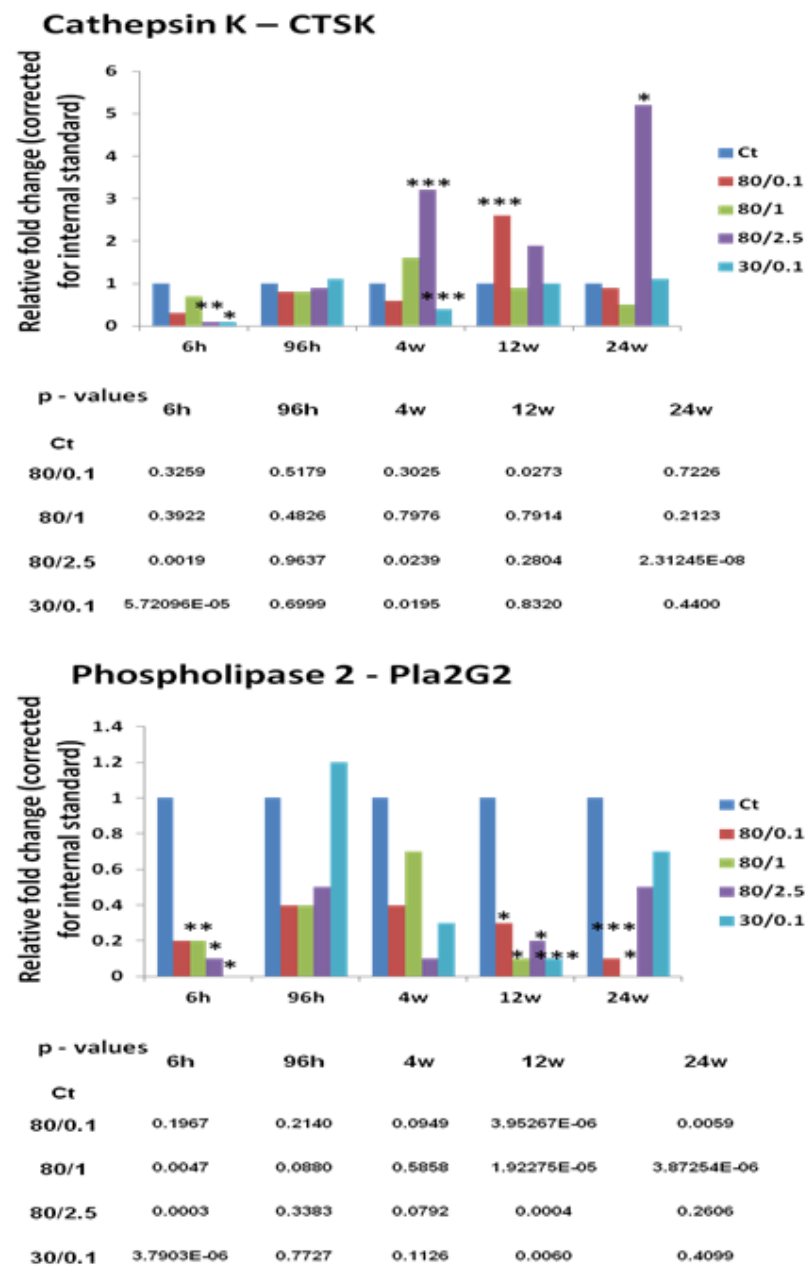

expression after high dose/energy level ( $80 \mathrm{kVp} / 2.5 \mathrm{~Gy})$ and low dose/low energy level $(30 \mathrm{kVp} / 0.1 \mathrm{~Gy})$ radiation (Table 3). Upregulation of miR-34a has been found to be common for both doses, and the expression level has been increased 1.55- and 1.08-fold after $80 \mathrm{kVp} / 2.5$ Gy and $30 \mathrm{kVp} / 0.1 \mathrm{~Gy}$, respectively. MiR-34a directly inhibits the expression of transcription factor E2F3 that is necessary for cell progression through cell cycle and the expression of actin cross-linking protein, transgelin, which may contribute to the replicative senescence. The MiR34 family is known to be activated by the p53-dependant pathway in response to DNA damage.

\section{Tp53, E2F3, and transgelin expression in the irradiated mammary gland}

The elevated expression of miR-34a was interesting to us, and we decided to proceed with identifying protein levels of its targets E2F3 and transgelin as well as p53, the key protein in DNA damage response. Western analysis
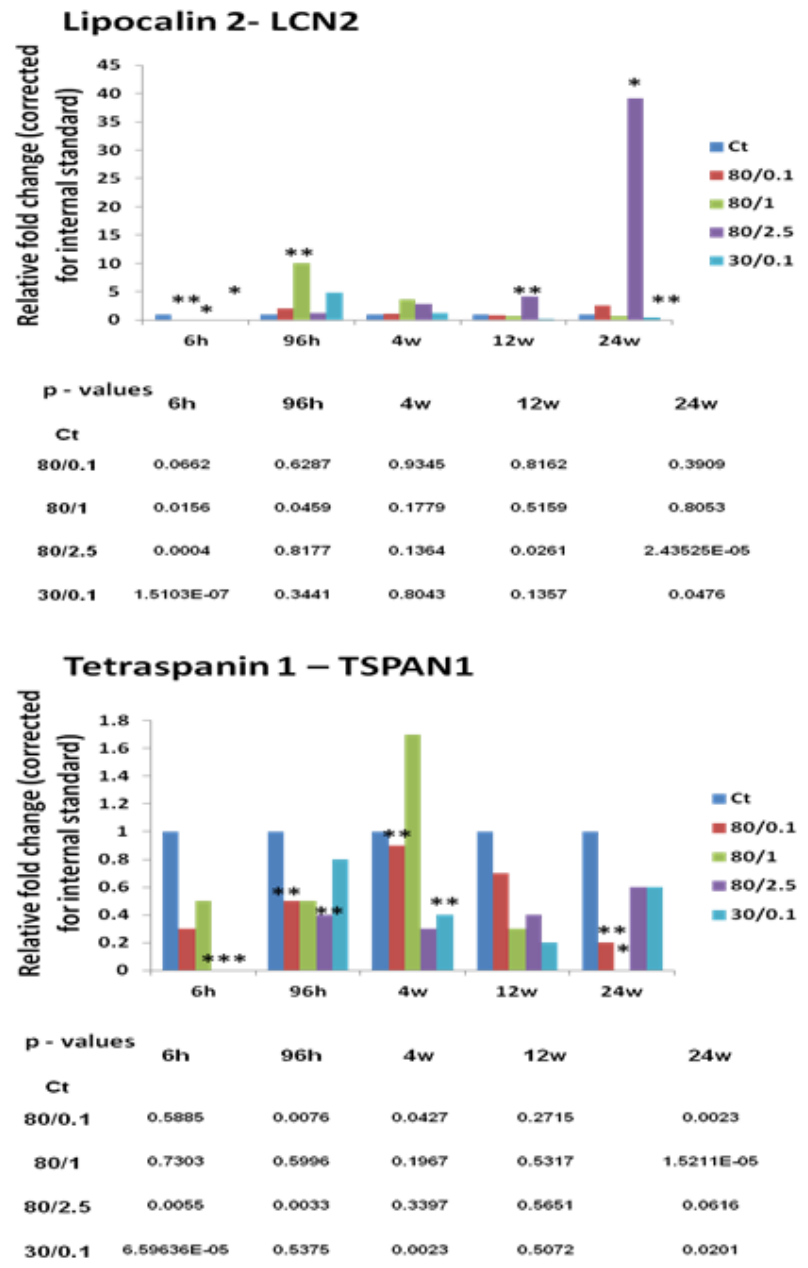

Figure 3: The altered levels of gene transcripts of cathepsin K, lipocalin 2, phospholipase 2, and tetraspanin 1 as detected by RT-PCR. The data are shown as fold changes to respective controls. Each treatment group was compared to its corresponding control; B-actin was used as a reference gene (calculated by Pfaffl). P-values (in the tables below the graphs) were calculated by Student's t-test. 
Table 3: Radiation-induced microRNA expression changes in rat mammary gland. Relative miR expression values are represented in folds in the irradiated cells in comparison to non-irradiated control cells as analyzed by miRNA microarray. Significance of differences was analyzed by the Student's t-test.

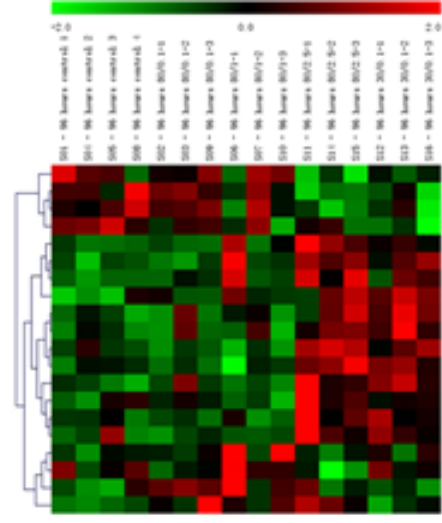

p-value $<0.10$

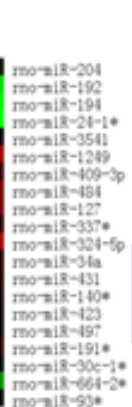

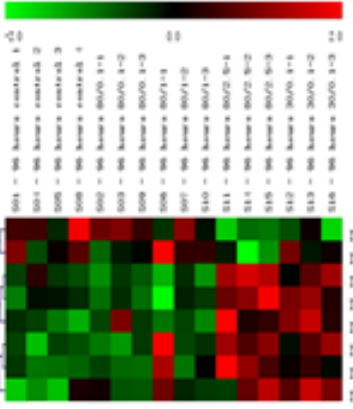

p-value $<0.05$

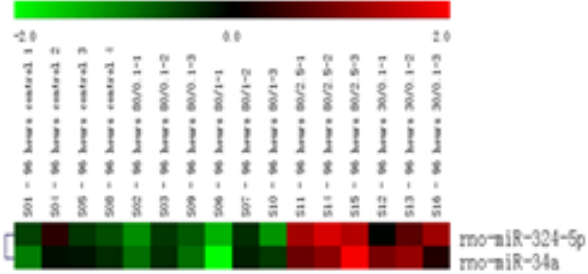

p-value $<0.01$

\begin{tabular}{|c|c|c|c|}
\hline Treatment Group & MiRNA changed & $\log 2(\mathrm{G} / \mathrm{CT})$ & Validated targets \\
\hline $80 \mathrm{kVp} / 0.1 \mathrm{~Gy}$ & 2 & Low fold change & - \\
\hline $80 \mathrm{kVp} / 1 \mathrm{~Gy}$ & Low signals & - & - \\
\hline $80 \mathrm{kVp} / 2.5 \mathrm{~Gy}$ & $\begin{array}{l}\text { miR-34a } \\
\text { miR-29c } \\
\text { miR-20b-5p } \\
\text { miR-204 }\end{array}$ & $\begin{array}{l}1.55 \\
-1.02 \\
-1.65 \\
-1.39\end{array}$ & $\begin{array}{c}\text { E2F3, Tagln, INHBB } \\
\text { Tpml } \\
- \\
-\end{array}$ \\
\hline $30 \mathrm{kVp} / 0.1 \mathrm{~Gy}$ & $\begin{array}{c}\text { miR-34a } \\
\text { miR-20b-5p } \\
\text { miR-98 } \\
\text { miR-127 }\end{array}$ & $\begin{array}{r}1.08 \\
-1.55 \\
-1.16 \\
2.08\end{array}$ & $\begin{array}{c}\text { E2F3, Tagln, INHBB } \\
- \\
- \\
-\end{array}$ \\
\hline
\end{tabular}

was performed for tissues exposed to $80 \mathrm{kVp} / 2.5 \mathrm{~Gy}$ and $30 \mathrm{kVp} / 0.1$ Gy radiation, at 96 hours and 24 weeks after exposure. The level of Tp53 was shown to be significantly elevated at 24 hours after low-dose exposure (Fig. 4). The increased levels of the phosphorylated $\mathrm{p} 53$ protein stimulated radiation response and DNA damage repair.

The level of E2F3 protein was shown to be decreased in response to both $80 \mathrm{kVp} / 2.5$ Gy and $30 \mathrm{kVp} / 0.1$ Gy radiation treatments at early time point (96 hours) (Fig. 4). The downregulation of E2F3 is known to stimulate G1 arrest, senescence, and/or apoptosis. There were no significant differences in the expression of transgelin in the irradiated tissues in comparison to nonirradiated controls (Fig. 4).

\section{DISCUSSION}

Ionizing radiation has been successfully used in 
medical tests and treatment modalities for a variety of medical conditions, including breast cancer screening and therapy. Nevertheless, a strong concern about overexposure to medical ionizing radiation and possible cancer induction due to continuous mammography procedures and/or CT scans exists amongst patients and individuals who provide patient care [4]. The raised concern is based on the ability of low doses of ionizing radiation used for diagnostic procedures to cause DNA damages that are not extensive enough to induce cell death but may result in mutations, genomic rearrangements and cancer initiation [17]. Ionizing radiation is considered to be a non-threshold carcinogen. The Linear-No-Threshold (LNT) model states that there is no dose level below which radiation exposure is safe, and there is a finite probability that even the lowest possible dose may be responsible for cancer initiation [4]. It is evident that choosing the right dose of radiation as well as the amount of radiation used during screening and therapy is vital for any medical procedure to minimize any potential risk of harm. Overall, the data on the response of healthy mammary tissues to low versus high doses and energy levels of radiation are scarce and indeed need more experimental evidence.

In the present study, the immediate (96 hours) and prolonged (24 weeks) radiation-induced changes in mammary gland gene expression were investigated and compared between different radiation doses and energy levels. Unexpectedly, the large-scale gene expression alterations were only noticed after the application of high energy/low dose $(80 \mathrm{kVp} / 0.1 \mathrm{~Gy}) \mathrm{X}$-rays at 96 hours after treatment (Table 1). Neither high-dose nor lowdose exposures combined with low-energy radiation caused significant modifications in gene expression at the transcription level. The altered genes mainly constituted the immunological pathways that were shown to be activated upon radiation (Table 2). Radiation is generally considered to be an immunosuppressive agent that kills radiosensitive cells, and this makes radiotherapy one of the most successful cancer therapies. However, under certain circumstances, especially exposure to low-dose radiation may enhance immunity. Our study has shown an increase in antigen processing and presentation, a

A.
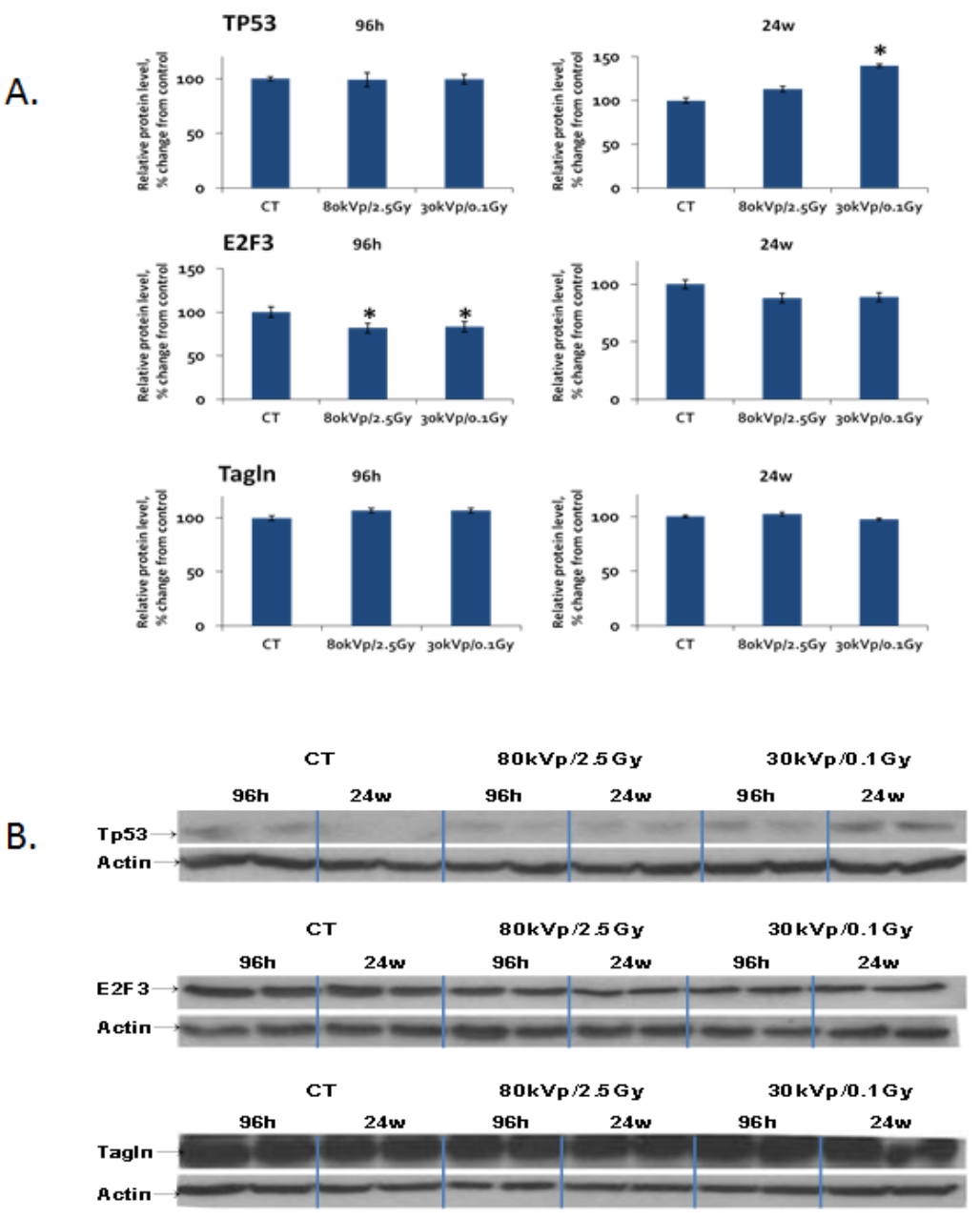

Figure 4: The levels of Tp53, E2F3 and transgelin protein in the rat mammary gland upon whole-body irradiation. Protein levels relative to those of control non-irradiated animals are shown as Mean \pm St Er. Representative blots are shown of two independent experiments. ${ }^{*}-\mathrm{p}<0.05$, the Student's t-test. 
process by which antigen-presenting cells digest foreign proteins and display antigenic peptide fragments on $\mathrm{MHC}$ molecules for the recognition by $\mathrm{T}$ cells during infections and abnormal cell growth. Among the genes that were upregulated and contribute to this pathway were the following: CD74 (the major histocompatibility complex class two that plays a role in MHCII antigen processing), CD8a (involved in T cell-mediated killing by identifying cytotoxic T cells that interact with MHC class I), Ifi30 (the interferon gamma inducible protein that facilitates $\mathrm{MHC}$ class I and II recognition of antigens containing disulfide bonds), and other genes with similar functions. A similar effect of radiation on antigen presentation by MHC class I was reported previously in murine colon adenocarcinoma cells [18]. Similarly, non-cytotoxic effects of ionizing radiation on $\mathrm{MHC}$ class I antigen presentation were demonstrated in bone marrow-derived dendritic cells [19]. The modulation of antigen presentation pathways provides protective anti-tumor immunity to the irradiated cells and tissues. Eighteen genes constituting the natural killer (NK) cell-mediated cytotoxicity pathway were also upregulated (Table 2, Fig. 2). NK cells play a role in immune surveillance for cancer by providing anticancer immunity to cells [20]. The activated genes were CD247 (it plays a role in signal transduction upon antigen triggering), Icam 1 and 2 (they are ligands for leukocyte adhesion), lat (a linker for $\mathrm{T}$ activation), among others. The enhancement of NK cell-mediated cytotoxicity after radiation in combination with HDAC inhibitor was recently reported in lung cancer cells [21]. B- and T-cell receptor signaling pathways were also upregulated upon low dose/high energy radiation (Table 2). Both pathways stimulate immune response to cancer initiation and are the prime targets for the treatment of many malignancies. Various chemoattractants for blood monocytes and memory T-helper cells as well as chemokine receptor genes were activated; this activation upregulated the chemokine signaling pathway (Table 2). Similar CXC chemokines were shown to be upregulated by extremely low doses of ionizing radiation in normal human fibroblasts [22]. The upregulation of the phogocytosis pathway was due to an increased expression of 11 genes. Phagocytosis activation has been known to be induced after radiation exposure as a consequence of recognition and clearance of radiation-induced apoptotic cells. Such inflammatorytype response to radiation exhibits the bystander effect of radiation rather than the direct effect of radiation [23]. Overall, the activation of immune response pathways upon radiation exposure may indicate anti-tumor protection and eradication of damaged cells. Similar effects of internal low-dose irradiation on gene expression and activation of immune response in normal tissues in mice were reported previously [3]. Interestingly, immune response was the only common biological process affected by irradiation in all tissues studied (the liver, lung, spleen, kidney medulla, and kidney cortex), while alterations in other biological processes were tissue-specific [3].

Radiation response has also shown metabolic changes, mainly downregulation of citrate cycle, pyruvate, and fatty acid metabolism pathways (Table 2). A metabolic response to radiotherapy is very important. A progressive decrease in glucose metabolism in cancer has been shown to be useful for the prediction of radiotherapy response [24]. Metabolic properties of pre-cancerous and cancer cells depend on glycolisis, increased fatty acids synthesis, and increased rates of glutamine metabolism. These properties often result in therapeutic resistance [25]. Our results on gene expression have demonstrated the radiation-induced metabolic inhibition that may lead to cell death rather than cancer initiation. Gene expression analysis was confirmed by qRT-PCR for four genes with the highest changes in gene expression. Tetraspanin 1 RNA expression was proved to be decreased upon ionizing radiation (Fig. 3). This protein mediates signal transduction events that play a role in the regulation of cell development, activation, growth, and motility. Phospholipase 2 was down-regulated at the early and late time points, and was thought to participate in the regulation of phospholipid metabolism in biomembranes, including eicosanoid biosynthesis. Phospholipases are ubiquitously expressed and have diverse biological functions, including the roles in inflammation, cell growth, signaling and death, and the maintenance of membrane phospholipids. Interestingly, both gene expression and qRT-PCR analyses have shown an increased expression of lipocalin 2 and cathepsin K 24 weeks after being exposed to the highest dose $(80 \mathrm{kVp} / 2.5 \mathrm{~Gy})$. Both proteins are known to be oncogenes and are ubiquitously expressed in breast cancers. It is important to note that high expression of these genes was not accompanied by the upregulation of particular pathways to which these genes belong.

It is well accepted that gene expression is strongly regulated by epigenetic factors [26]. A number of studies have indicated substantial alterations of epigenetic elements, including changes in DNA methylation, histone modification, and short RNA patterns as a result of radiation exposure [27]. Radiation-induced changes in miRNA expression usually lead to changes in the synthesis of proteins involved in the main cellular biological pathways. As per Table 3, the validated targets of misregulated miRNAs fall in cell cycle and apoptosis categories (Table 3). Interestingly, a low radiation dose causes similar miRNA expression changes to the highest dose. The increased expression of miR-34a may be linked to cell cycle arrest and apoptosis. The ectopic expression of miR-34 genes is known to cause a G1 phase arrest [28]. Furthermore, the high expression of miR-34a has been shown to induce apoptosis [29]. The main targets of miR-34a are E2F3 transcription factor, transgelin, and possibly CDK4/6, cyclin E2, c-myc [30]. Bommer et al. showed that Bcl-2 was targeted by miR-34a [31]. Interestingly, several reports have shown that the miR-34 
family is a direct target of p53, and its activation induces apoptosis and cell cycle arrest $[31,32]$. In addition, the activation of miR34-a by p53 feeds back to p53, and such positive feedback leads to further activation of p53 [30]. We further decided to conduct Western blot analysis to identify protein levels of E2F3 and transgelin that are targets of p53 and miR-34a targets, E2F3 and transgelin. The expression level of E2F3 protein was indeed downregulated at 96 hours after radiation treatment with both low and high doses (Fig. 4). E2F3 binds specifically to $\mathrm{RB} 1$ and is involved in the control of cell cycle progression from $\mathrm{G} 1$ to $\mathrm{S}$ phase. Low levels of E2F3 lead to cell cycle arrest in response to DNA damages that result from ionizing radiation. We did not notice any significant changes in the protein level of transgelin. However, an elevated level of p53 protein was detected after exposure to a low dose of ionizing radiation. Such correlation between upregulated miR-34a, the downregulation of its target E2F3, and the upregulation of p53 allows us to suggest that ionizing radiation at specific high and low doses leads to cell cycle arrest and a possible initiation of apoptosis. The induction of cell cycle arrest and promotion of apoptosis when the damage is too severe to be repaired are considered to be important for tumor suppression [33]. In his report, Hermeking described the role of p53 as a mediator of tumor suppression through the activation of miR-34 family members.

Overall, both post radiation gene expression and miRNA expression analyses have demonstrated an increased immunological response and cell cycle arrest directed to prevent cancer initiation. However, these characteristics were not detected for every dose applied. Further investigation of the cellular response may shed more light on the correlation between differential radiation doses and their effects on apoptosis/cancer.

\section{MATERIALS AND METHODS}

\section{Animal models and irradiation conditions}

Six-week-old intact female Long-Evans rats were obtained from Charles River (Wilmington, MA). The animals were housed two per cage in a temperaturecontrolled $\left(24{ }^{\circ} \mathrm{C}\right)$ room in a 12-hour light-dark cycle and given ad libitum access to water and an NIH-31 pelleted diet. Six rats were randomly assigned to one of the following X-ray radiation treatment groups: $80 \mathrm{kVp} / 0.1$ Gy, $80 \mathrm{kVp} / 1 \mathrm{~Gy}, 80 \mathrm{kVp} / 2.5 \mathrm{~Gy}, 30 \mathrm{kVp} / 0.1 \mathrm{~Gy}$, and sham treated controls. Each group of animals was humanely sacrificed 6, 96 hours, and 4, 12, and 24 weeks after radiation treatment. The paired caudal inguinal mammary glands were excised. Tissue was frozen immediately in liquid nitrogen and stored at $-80^{\circ} \mathrm{C}$ for subsequent analyses.

\section{RNA isolation}

Total RNA was isolated using the Illustra RNAspin Mini kit (GE Healthcare Life Sciences, Buckinghamshire, UK). Approximately 50-70 mg of mammary gland tissue was processed following the manufacturer's instructions. The samples were eluted in Ultrapure DNase/RNasefree distilled water provided in the kit. RNA samples were quantified by ultraviolet spectroscopy (NanoDrop, Wilmington, DE) and were further assessed for RNA integrity (RIN) on the Aglient 2100 Bioanalyzer (Santa Clara, CA) using the RNA Nano-chip Kit. RNA samples with RIN values of seven or better were followed through to analysis.

\section{Whole-genome gene expression profiling}

\section{Library preparation}

For this study, cRNA was created using the Ambion Illumina TotalPrep RNA Amplification Kit (Applied Biosystems, Carlsbad, CA), with an input of $500 \mathrm{ng}$ of total RNA per sample. Briefly, oligo-dT primers were used to synthesize first-strand cDNA containing a phage T7 promoter sequence. The single-stranded cDNA was converted into a double-stranded DNA template via DNA polymerase. RNase $\mathrm{H}$ acted simultaneously to degrade RNA, and cDNA samples were purified in filter cartridges to remove excess RNA, primers, enzymes, and salts. The recovered cDNA was subjected to in vitro transcription using biotinylated UTPs. This step created the labeled and amplified cRNA. A final purification step removed unincorporated NTPs, salts, inorganic phosphates, and enzymes to prepare samples for hybridization.

\section{Hybridization and detection}

The Illumina's direct hybridization assay kit was used to process samples according to the manufacturer's protocol (Illumina, San Diego, CA). Briefly, $750 \mathrm{ng}$ from each cRNA sample was hybridized to the Illumina RatRef-12 Whole Genome Expression BeadChip arrays overnight. Afterward, a 10-minute incubation with the supplied wash buffer at $55^{\circ} \mathrm{C}$ preceded a 5-minute roomtemperature wash. The arrays were incubated in $100 \%$ ethanol for 10 minutes. A second room temperature wash for two minutes with gentle shaking completed this high stringency wash step. The arrays were blocked with buffer for 10 minutes and washed before a 10-minute probing with steptavidin-Cy3 (1:1000). After a five-minute wash at room temperature, BeadChips were dried and imaged. Six controls were also built into the Whole-Genome Gene Expression Direct Hybridization Assay system to cover 
the aspects of array experiments. These included controls for a biological specimen (14 probes for housekeeping controls), three controls for hybridization (six probes for Cy3-labeled hybridization, four probes for low stringency hybridization, one probe for high stringency hybridization), signal generation (two probes for biotin control) and $\sim 800$ probes for negative controls on an eight-sample BeadChip. The arrays were scanned on the iScan platform (Illumina), and the data were normalized and scrutinized using Illumina BeadStudio software.

\section{BeadChip statistical analysis and data processing}

The false discovery rate (FDR) was controlled by the Benjamini-Hochberg method. The Illumina Custom Model took FDR into account and was used to analyze the data. Differential gene expression (at least a 0.5 -fold change) from sham-treated animals was determined to be statistically significant if the p-value after the adjustment with the Benjamini-Hochberg method was less than 0.05. The values were transformed to show a $\log 2$ scale.

Lists of regulated transcripts were put into the webbased DAVID Bioinformatics Resources 6.7 (NIAID/NIH) Functional Annotation Tool [11, 12]. This program was used to group genes into functionally relevant categories and pathways for further analysis of the association of genetic profiles with breast cancer susceptibility. The minimum number of genes in each altered pathway was set to three. The pathways were deemed significantly altered if at least $80 \%$ of the genes were shifting the pathway in the same direction [13].

\section{Real-time polymerase chain reaction (qRT-PCR)}

Quantitative real-time PCR was performed to confirm the Whole-Genome Gene Expression results for the regulation and direction (either up or down) of the selected genes. Four genes (Cathepsin K, Lipocalin 2, Phospholipase 2, and Tetraspanin 1) were selected from the gene list of significantly differentially expressed transcripts that represented a preliminary review of the acquired gene expression data. $\beta$-Actin was used as a reference gene. All reactions were performed using cDNA synthesized from 500 ng of RNA sample using the Bio-Rad iScript Select cDNA Synthesis Kit (Bio-Rad Laboratories, Hercules, CA). The samples were stored at $-20^{\circ} \mathrm{C}$ for long-term storage and at $4^{\circ} \mathrm{C}$ until they were used for subsequent qRT-PCR reactions.

The primers were designed using the NCBI database and PrimerQuest (Integrated DNA Technologies, Inc., Coralville, IA). The primers were as follows: CTSK forward primer 5'-ATG TGC AGC AGA ATG GAG GCA TTG-3' and reverse primer 5'-TGC TCT CTT CAG GGC TTT CTC GTT-3'; LCN2 forward primer 5' -ACA ACG TCA CTT CCA TCC TCG TCA- 3' and reverse primer
5' -TGG CAA ACT GGT CGT AGT CAG TGT- 3'; $P L A 2 G 2 A$ forward primer 5' -CAT GGC CTT TGG CTC AAT TCA GGT- 3' and reverse primer 5' -ACA GTC ATG AGT CAC ACA GCA CCA- 3'; TSPAN forward primer 5' -TTG TCA ACG TGG GCT ACT TCC TCA- 3' and reverse primer 5' -AGC ACA CAC TTG TTC TCG GAG TGA- 3'; and beta-Actin reference gene forward primer 5'-CCT CTG AAC CCT AAG GCC AA-3' and reverse primer 5'-AGC CTG GAT GGC TAC GTA CA-3'. Reactions were prepared using $1 \mathrm{~L}$ of diluted cDNA, 10 $\mathrm{pmol} / \mathrm{L}$ of each forward and reverse primer and Ssofast EvaGreen Supermix (Bio-Rad Laboratories, Hercules, CA) according to the manufacturer's instructions. Samples were prepared in triplicate and were run on the Bio-Rad C1000 Thermal Cycler equipped with the CFX96 Real-Time System. The qRT-PCR protocol consisted of denaturation at $95^{\circ} \mathrm{C}$ for two minutes; 43 cycles of denaturation $\left(95^{\circ} \mathrm{C}\right.$, five seconds) and annealing/ extension ( $55 \mathrm{C}$, five seconds); and the final extension at $65^{\circ} \mathrm{C}$ for five seconds. For every set of primers, annealing temperature optimization, melting curve analysis, and gel analysis of amplicon were performed. To evaluate PCR efficiency, the standard curve was established using series of cDNA dilutions. The data were captured and organized by the Bio-Rad CFX Manager 2.1 software (Bio-Rad Laboratories, Hercules, CA).

The quantification data from the Bio-Rad CFX Manager software were analyzed in Microsoft Excel using the Pfaffl method [14]. The graphs showing fold change from the sham group were created showing transcript regulation directions (up- or down regulation).

\section{miRNA microarray expression analysis}

Total RNA from mammary gland frozen tissues was isolated using Trizol reagent (Invitrogen, Burlington, ON) according to the manufacturer's instructions. One ug of the total extracted RNA represented as two repeats per experimental group was sent to LC Sciences (Austin, TX) for miRNA microarray analysis.

\section{Western immunoblotting}

For protein isolation, 30-50 $\mathrm{mg}$ of mammary gland tissue were washed in PBS, lysed, and sonicated in $0.25 \mathrm{~mL}$ of $1 \%$ sodium dodecyl sulfate (SDS) containing protein inhibitors. The lysates were cleared using centrifugation. The protein content was determined using the Bradford protein determination assay (BioRad, Hercules, CA). Equal amounts of lysate protein were subsequently run on 10-12\% SDS-polyacrylamide gels and transferred to PVDF membranes (GE Healthcare, Baied'Urfé, Québec).

Western immunoblotting was conducted using the well-established protocols $[15,16]$. The membranes were 
incubated with antibodies against mouse anti-TP53, rabbit anti-transgelin, rabbit anti-E2F3 (1:100 dilution, Santa Cruz Biotechnology, Inc., Santa Cruz, CA ), and mouse anti-Actin (1:1000 dilution, Abcam Inc., Cambridge, MA). Antibody binding was revealed through the incubation with horseradish peroxidase-conjugated secondary antibodies (GE Healthcare, Piscataway, NJ) and the ECL Plus immunoblotting detection system (GE Healthcare, Piscataway, NJ). Chemiluminescence was detected using BioMax MR films (Eastman Kodak, New Haven, CT). The unaltered PVDF membranes were stained with Coomassie Blue (BioRad, Hercules, CA) to prove equal protein loading. Signals were quantified using NIH Image J 1.63 software and normalized to loading controls. The images are representative of two independent immunoblots. The results are presented as mean \pm S.E.M. The statistical analyses were conducted using the student's t-test. P-values less than 0.05 were considered significant

\section{ACKNOWLEDGEMENTS}

We thank Dr. Yaroslav Ilnytskyy for his assistance in animal irradiation and mammary tissue collection, and to Dr. Valentina Titova for proof-reading the manuscript. Study was supported by the Canadian Institutes for Health Research and the Department of Energy Low Dose Radiation program grants to Dr. Olga Kovalchuk. Lidia Luzhna was supported by the ACF Graduate Scholarship.

\section{Conflict of Interest}

There is no conflict of interest that I should disclose, having read the above statement.

\section{REFERENCES}

1. Camphausen KA and Lawrence RC. Principles of radiation therapy. Cancer Management: a Multidisciplinary approach 11. 2008.

2. Brenner DJ and Hall EJ. Computed tomography--an increasing source of radiation exposure. N Engl J Med. 2007; 357(22):2277-2284.

3. Schuler E, Parris TZ, Rudqvist N, Helou K and ForssellAronsson E. Effects of internal low-dose irradiation from $131 \mathrm{I}$ on gene expression in normal tissues in Balb/c mice. EJNMMI Res. 2011; 1(1):29.

4. Mullenders L, Atkinson M, Paretzke H, Sabatier L and Bouffler S. Assessing cancer risks of low-dose radiation. Nature reviews. 2009; 9(8):596-604.

5. Calabrese EJ and Baldwin LA. Hormesis: the dose-response revolution. Annu Rev Pharmacol Toxicol. 2003; 43:175197.

6. Kruse JJ, te Poele JA, Russell NS, Boersma LJ and Stewart FA. Microarray analysis to identify molecular mechanisms of radiation-induced microvascular damage in normal tissues. Int J Radiat Oncol Biol Phys. 2004; 58(2):420-426.

7. Uehara $\mathrm{Y}$, Ito $\mathrm{Y}$, Taki K, Nenoi M, Ichinohe K, Nakamura S, Tanaka S, Oghiso Y, Tanaka K, Matsumoto T, Paunesku T, Woloschak GE and Ono T. Gene expression profiles in mouse liver after long-term low-dose-rate irradiation with gamma rays. Radiat Res. 2010; 174(5):611-617.

8. Shin SC, Lee KM, Kang YM, Kim K, Lim SA, Yang KH, Kim JY, Nam SY and Kim HS. Differential expression of immune-associated cancer regulatory genes in low- versus high-dose-rate irradiated AKR/J mice. Genomics. 2011; 97(6):358-363.

9. Ilnytskyy Y, Zemp FJ, Koturbash I and Kovalchuk O. Altered microRNA expression patterns in irradiated hematopoietic tissues suggest a sex-specific protective mechanism. Biochem Biophys Res Commun. 2008; 377(1):41-45.

10. Cha HJ, Shin S, Yoo H, Lee EM, Bae S, Yang KH, Lee SJ, Park IC, Jin YW and An S. Identification of ionizing radiation-responsive microRNAs in the IM9 human B lymphoblastic cell line. Int J Oncol. 2009; 34(6):1661-1668.

11. Huang da W, Sherman BT and Lempicki RA. Systematic and integrative analysis of large gene lists using DAVID bioinformatics resources. Nat Protoc. 2009; 4(1):44-57.

12. Huang da W, Sherman BT and Lempicki RA. Bioinformatics enrichment tools: paths toward the comprehensive functional analysis of large gene lists. Nucleic Acids Res. 2009; 37(1):1-13.

13. Kars MD, Iseri OD, Ural AU, Avcu F, Beyzadeoglu M, Dirican B and Gunduz U. Development of radioresistance in drug resistant human MCF-7 breast cancer cells. J Radiotherapy Practice. 2009; 8:207-213.

14. Pfaffl MW. A new mathematical model for relative quantification in real-time RT-PCR. Nucleic Acids Res. 2001; 29(9):e45.

15. Ertel A, Verghese A, Byers SW, Ochs M and Tozeren A. Pathway-specific differences between tumor cell lines and normal and tumor tissue cells. Mol Cancer. 2006; 5(1):55.

16. Tryndyak VP, Kovalchuk $\mathrm{O}$ and Pogribny IP. Loss of DNA methylation and histone $\mathrm{H} 4$ lysine 20 trimethylation in human breast cancer cells is associated with aberrant expression of DNA methyltransferase 1, Suv4-20h2 histone methyltransferase and methyl-binding proteins. Cancer Biol Ther. 2006; 5(1):65-70.

17. Ward JF. Radiation mutagenesis: the initial DNA lesions responsible. Radiat Res. 1995; 142(3):362-368.

18. Reits EA, Hodge JW, Herberts CA, Groothuis TA, Chakraborty M, Wansley EK, Camphausen K, Luiten $\mathrm{RM}$, de Ru AH, Neijssen J, Griekspoor A, Mesman E, Verreck FA, Spits H, Schlom J, van Veelen P, et al. Radiation modulates the peptide repertoire, enhances MHC class I expression, and induces successful antitumor immunotherapy. J Exp Med. 2006; 203(5):1259-1271.

19. Liao YP, Wang CC, Butterfield LH, Economou JS, Ribas A, Meng WS, Iwamoto KS and McBride WH. Ionizing 
radiation affects human MART-1 melanoma antigen processing and presentation by dendritic cells. J Immunol. 2004; 173(4):2462-2469.

20. Schmitt C, Ghazi B and Bensussan A. NK cells and surveillance in humans. Reprod Biomed Online. 2008; 16(2):192-201.

21. Son CH, Keum JH, Yang K, Nam J, Kim MJ, Kim SH, Kang CD, Oh SO, Kim CD, Park YS and Bae J. Synergistic enhancement of NK cell-mediated cytotoxicity by combination of histone deacetylase inhibitor and ionizing radiation. Radiat Oncol. 2014; 9:49.

22. Fujimori A, Okayasu R, Ishihara H, Yoshida S, EguchiKasai K, Nojima K, Ebisawa $\mathrm{S}$ and Takahashi $\mathrm{S}$. Extremely low dose ionizing radiation up-regulates CXC chemokines in normal human fibroblasts. Cancer Res. 2005; 65(22):10159-10163.

23. Lorimore SA, Coates PJ, Scobie GE, Milne G and Wright EG. Inflammatory-type responses after exposure to ionizing radiation in vivo: a mechanism for radiation-induced bystander effects? Oncogene. 2001; 20(48):7085-7095.

24. Giovacchini G, Picchio M, Schipani S, Landoni C, Gianolli L, Bettinardi V, Di Muzio N, Gilardi MC, Fazio F and Messa C. Changes in glucose metabolism during and after radiotherapy in non-small cell lung cancer. Tumori. 2009; 95(2):177-184.

25. Zhao Y, Butler EB and Tan M. Targeting cellular metabolism to improve cancer therapeutics. Cell Death Dis. 2013; 4:e532.

26. Jaenisch R and Bird A. Epigenetic regulation of gene expression: how the genome integrates intrinsic and environmental signals. Nat Genet. 2003; 33 Suppl:245-254.

27. Aypar U, Morgan WF and Baulch JE. Radiation-induced epigenetic alterations after low and high LET irradiations. Mutat Res. 2011; 707(1-2):24-33.

28. Tarasov V, Jung P, Verdoodt B, Lodygin D, Epanchintsev A, Menssen A, Meister G and Hermeking H. Differential regulation of microRNAs by $\mathrm{p} 53$ revealed by massively parallel sequencing: miR-34a is a p53 target that induces apoptosis and G1-arrest. Cell Cycle. 2007; 6(13):15861593.

29. Raver-Shapira N, Marciano E, Meiri E, Spector Y, Rosenfeld N, Moskovits N, Bentwich Z and Oren M. Transcriptional activation of miR-34a contributes to p53mediated apoptosis. Mol Cell. 2007; 26(5):731-743.

30. Hermeking H. The miR-34 family in cancer and apoptosis. Cell Death Differ. 2010; 17(2):193-199.

31. Bommer GT, Gerin I, Feng Y, Kaczorowski AJ, Kuick R, Love RE, Zhai Y, Giordano TJ, Qin ZS, Moore BB, MacDougald OA, Cho KR and Fearon ER. p53-mediated activation of miRNA34 candidate tumor-suppressor genes. Curr Biol. 2007; 17(15):1298-1307.

32. Corney DC, Flesken-Nikitin A, Godwin AK, Wang W and Nikitin AY. MicroRNA-34b and MicroRNA-34c are targets of p53 and cooperate in control of cell proliferation and adhesion-independent growth. Cancer Res. 2007; 67(18):8433-8438.

33. Vousden KH and Lane DP. p53 in health and disease. Nat Rev Mol Cell Biol. 2007; 8(4):275-283. 